\title{
Synthetic Nano-Low Density Lipoprotein as Targeted Drug Delivery Vehicle for Glioblastoma Multiforme
}

Mina Nikanjam ${ }^{1,3}$, Eleanor A. Blakely ${ }^{2}$, Kathleen A. Bjornstad ${ }^{2}$, Xiao Shu ${ }^{3}$,Thomas F. Budinger ${ }^{1,2}$,

Trudy M. Forte ${ }^{2,3}$

${ }^{1}$ Department of Bioengineering, University of California, Berkeley

${ }^{2}$ Lawrence Berkeley National Laboratory, Berkeley, California

${ }^{3}$ Children's Hospital of Oakland Research Institute, Oakland, California

Corresponding author:

Trudy M. Forte, Ph.D.

Children's Hospital of Oakland Research Institute

5700 Martin Luther King Junior Way

Oakland, CA 94609

TEL: (510) 450-7610

FAX: (510) 450-7910

Email: tforte@chori.org

Keywords: low density lipoprotein; low density lipoprotein receptor; glioblastoma multiforme; microemulsion; peptide; nano-low density lipoprotein 


\begin{abstract}
The low density lipoprotein (LDL) receptor has been shown to be upregulated in GBM tumor cells and is therefore a potential molecular target for the delivery of therapeutic agents. A synthetic nano-LDL (nLDL) particle was developed and tested to determine its utility as a drug delivery vehicle targeted to GBM tumors. nLDL particles were constructed by combining a synthetic peptide containing a lipid binding motif and the LDL receptor (LDLR) binding domain of apolipoprotein B-100 with a lipid microemulsion consisting of phosphatidyl choline, triolein, and cholesteryl oleate. Composition analysis, fast protein liquid chromatography, and electron microscopy revealed that nLDL was highly reproducible and intermediate in size between high density lipoprotein and LDL particles $(10.5 \pm 2.8 \mathrm{~nm}$ diameter $)$. The binding and uptake of fluorescently labeled nLDL particles was assessed using fluorescence microscopy. Uptake of nLDL was time dependent, exhibiting saturation at approximately $3 \mathrm{~h}$, and concentration dependent, exhibiting saturation at concentrations greater than $5 \mu \mathrm{M}$ peptide. Using Lysotracker as a cellular marker, nLDL co-localized with lysosomes. nLDL binding was eliminated by blocking LDLRs with suramin and nLDL inhibited binding of plasma LDL to LDLRs. Collectively these data strongly suggest that the synthetic nano-LDLs described here are taken up by LDLR and can serve as a drug delivery vehicle for targeting GBM tumors via the LDLR.
\end{abstract}




\section{Introduction}

Glioblastoma multiforme (GBM) is a highly aggressive malignancy that accounts for approximately $85 \%$ of primary brain tumors in adults. Current treatment consisting of surgery, radiation and chemotherapy has had limited success and median survival time is approximately one year from diagnosis. A study on seven GBM cell lines showed that these cells have upregulated low density lipoprotein receptors (LDLR)s and that receptor numbers per cell varied between 125,000 and 950,000 receptors (Maletinska et al., 2000). Studies on the distribution of LDLR in normal rat and monkey brain tissue suggest that normal brain tissue, particularly neurons, has relatively low LDLR (Pitas et al., 1987). Thus is appears that the LDLR is a potential molecular target for the selective delivery of anti-tumor compounds to GBM.

Low density lipoprotein (LDL) is the major ligand for the LDLR and it is also the major transporter of cholesterol in the plasma. The cholesterol transported by LDL is used for cell growth and membrane repair. LDL is a $22-27 \mathrm{~nm}$ particle composed of a core of hydrophobic lipids, primarily cholesteryl esters with a small amount of triglyceride, and has a surface coat of phospholipids, unesterified cholesterol, and a single molecule of apolipoprotein B-100 (apoB) (Grundy, 1990). ApoB-100 is a 514,000 Dalton glycoprotein with 9 amino acids (3359-3367) serving as the binding domain for the LDL receptor (Segrest et al., 2001). Upon binding to LDLR in clathrin coated pits, LDL is internalized via endocytosis and moves into the endosome where a drop in $\mathrm{pH}$ causes the receptor to dissociate from the LDL. The receptor is recycled back to the surface of the cell while the LDL is moved into the lysosome where the particle is degraded (Goldstein et al., 1985). This pathway could be useful for the delivery and concentration of drugs into tumors expressing LDLR. 
Tumor cells generally have high cholesterol requirements as they are rapidly dividing cells. Increased LDL requirement and receptor activity has been observed in colon cancer (Niendorf et al., 1995), prostate tumors (Chen and Hughes-Fulford, 2001), adrenal tumors (Nakagawa et al., 1995), hormone unresponsive breast tumors (Stranzl et al., 1997), cancers of gynecological origin (Gal et al., 1981), lung tumor tissues (Vitols et al., 1992), leukemia (Tatidis et al., 2002, Vitols et al., 1994, Vitols et al., 1984, Ho et al., 1978), and malignant brain tumors (Rudling et al., 1990). It was previously suggested that plasma-derived LDL could be used as a drug delivery system for tumors expressing LDLR since its hydrophobic core has the possibility of incorporating lipophilic drugs (Firestone, 1994, Rensen et al., 2001). Drugs have been either directly loaded onto plasma LDL or the core lipids of LDL were replaced with drugs (Callahan et al., 1999, Ji et al., 2002, Chu et al., 2001, Vitols et al., 1985, Firestone et al., 1984, Dubowchik and Firestone, 1995, Vitols et al., 1990). Plasma LDL, however, is less than ideal as a targeting agent since it is difficult to isolate in large quantities and is variable in composition and size. Another approach used reconstituted LDL consisting of a lipid microemulsion containing drugs stabilized by purified apoB-100 (Lundberg, 1987, Lundberg, 1994, Lundberg and Suominen, 1984, Masquelier et al., 2006). The apoB-100 protein is difficult to isolate due to its large size and propensity to aggregate and is therefore not useful for generation of large batches of reconstituted LDL.

Recent studies have shown the feasibility of creating a synthetic LDL particle as a replacement for serum in cell culture media using a lipid microemulsion and a peptide composed of the LDLR binding domain of apoB (Baillie et al., 2002, Hayavi and Halbert, 2005). This synthetic 
particle was able to support cell growth by delivering cholesterol to cells via the LDL receptor. We hypothesized that a synthetic nano-LDL (nLDL) particle that mimics the binding and uptake properties of plasma-derived LDL could be useful for targeting GBM cells. In the present report, we describe a synthetic nano-LDL particle composed of a lipid microemulsion and a synthetic bifunctional peptide which contains a lipid binding domain and the nine amino acid LDLR binding domain. We demonstrate that these novel particles mimic the behavior of plasmaderived LDL and are capable of targeting the LDLR on GBM cells. 


\section{Materials and Methods}

\subsection{Materials:}

Triolein (TO), cholesteryl oleate (CO), 3,3'-dioctadecyloxacarbocyanine perchlorate (DiO), suramin, butylated hydroxytoluene (BHT), and 1\% fatty acid free bovine serum albumin (BSA) were obtained from Sigma. Lysotracker Blue DND 22 and 1,1'-dioctadecyl-3,3,3',3'tetramethylindocarbocyanine perchlorate (DiI) were obtained from Invitrogen (Molecular Probes). Egg yolk phosphatidyl choline (PC) was obtained from Avanti Polar Lipids. Plasmaderived LDL and high density lipoprotein (HDL) were obtained from Intracel (Frederick, MD).

\subsection{Peptide:}

The peptide used for production of nLDL was a chimera consisting of an 18-amino acid amphipathic alpha helix (Anantharamaiah et al., 1985) attached to the LDLR binding domain (Segrest et al., 2001). The complete 29 amino acid peptide sequence is as follows:

DWLKAFYDKVAEKLKEAFRLTRKRGLKLA. The underlined region is the LDLR binding domain. The peptide was obtained from Biosynthesis Inc. (Lewisville, TX) at greater than 95\% purity as determined by HPLC analysis. The amino terminus was capped with an acetyl group while the carboxy terminus was capped with an amine group.

\subsection{Production of synthetic nano-LDL (nLDL):}

Lipid microemulsions were formed using a modification to the method of Baillie et al (2002). The microemulsion consisted of $\mathrm{PC}, \mathrm{TO}$, and $\mathrm{CO}$ combined in a 3:2:1 mole ratio and dried under nitrogen. Tris-saline buffer (20 mM Tris, $\mathrm{pH} 7.2)$ was introduced into the dried lipids, and the solution was then 
vortexed for one minute on the high setting. BHT $(20 \mu \mathrm{M})$ was added and the solution sonicated (Branson Sonifier) for one hour, at setting 5, on ice, under nitrogen to disrupt large lipid complexes. Sonicated particles were spun, 20 minutes at $4000 \mathrm{rpm}$, to remove particulates. The lipid microemulsion was extruded using an Avanti Polar Lipids extruder, 20 times through a $0.1 \mu \mathrm{m}$ filter and then 20 times through a $0.03 \mu \mathrm{m}$ filter. The final microemulsion was filter sterilized using a $0.22 \mu \mathrm{m}$ filter. Microemulsion was combined with the synthetic peptide at $2.15 \mu \mathrm{M}$. The mixture was lightly vortexed for 1 minute and then incubated for 30 minutes at room temperature. Unbound peptide was removed by dialysis against Tris-saline buffer at $4^{\circ} \mathrm{C}$ with two changes at $24 \mathrm{~h}$ intervals.

\subsection{Size of nLDL particles:}

The size distribution of the synthetic particles was determined by fast protein liquid chromatography (FPLC) using a Superose 6 column. The column was connected to an Amersham Biosciences FPLC System (Pistcataway, NJ) and equilibrated in Tris-saline buffer (pH 7.2). After column equilibration, $0.2 \mathrm{~mL}$ of nLDL (approximately $0.15 \mathrm{mg}$ of protein) was injected. The sample flow rate was $0.5 \mathrm{~mL} / \mathrm{min}$ and absorbance was read at $280 \mathrm{~nm}$. Plasmaderived LDL and HDL were used as standards to calibrate the column.

Ultracentrifugation was utilized to remove lipid-poor particles from the lipid-rich nLDL. The nLDL preparation was adjusted to $\mathrm{d}=1.21 \mathrm{~g} / \mathrm{mL}$ and spun for $36 \mathrm{~h}$ at $40,000 \mathrm{rpm}\left(4^{\circ} \mathrm{C}\right)$ in a Beckman Ultracentrifuge using a Ti50.3 rotor. At the conclusion of the spin, the top $1 \mathrm{~mL}$ of the sample was collected by aspiration and dialyzed against Tris-saline buffer with two buffer changes; this fraction constitutes the nLDL fraction used in subsequent experiments. The size of 
particles was determined by negative staining electron microscopy as previously described (Forte and Nordhausen, 1986).

\subsection{Composition of nLDL particles:}

Lipid composition of the particles was determined for cholesterol, triglyceride, and phospholipid using enzymatic colorimetric assays from Wako (Richmond, VA). Protein was quantified by the Markwell modification of the Lowry Method (Lowry et al., 1951). Compositions of nLDL from three separate experiments were carried out to determine reproducibility of lipid and protein composition.

\subsection{Cell culture:}

Previously described GBM cells lines (SF-767, U-251, SF-763) were obtained from the tissue bank of the Brain Tumor Research Center (University of California San Francisco, CA) (Callahan et al., 1999). GBM cells were grown, $37^{\circ} \mathrm{C}, 5 \% \mathrm{CO}_{2}$, essentially as described by Callahan et al. (1999) in Eagle's Minimal Essential Medium (MEM) supplemented with 1\% nonessential amino acids, $1 \mathrm{~g} / \mathrm{L}$ glucose, $0.292 \mathrm{~g} / \mathrm{L}$ glutamine, $2.2 \mathrm{~g} / \mathrm{L}$ sodium bicarbonate, $10 \%$ fetal bovine serum, and antibiotics until needed for experiments. For most experiments, cells were plated at $5 \times 10^{4}$ cells per well on Lab-Tek II, two-well chamber slides or 12-well plates. For confocal microscopy, cells were plated at $2 \times 10^{4}$ cells on a polylysine coated coverslip in a 24-well plate. Cells were allowed to grow for $48 \mathrm{~h}$ before lipoprotein-deficient fetal bovine serum (LPDS) in above MEM was placed on the cells (Callahan et al., 1999). Experiments were conducted on exponentially growing cells, at approximately $70 \%$ confluency, $24 \mathrm{~h}$ after addition 
of LPDS media. At the conclusion of each experiment, cells were washed twice with PBS containing $1 \%$ fatty acid free BSA.

\subsection{Fluorescent labeling:}

Fluorescent labeling of the lipid moiety of nLDL with DiO or DiI was carried out essentially as described by Pitas et al (Pitas et al., 1981, Innerarity et al., 1986). After labeling, unbound fluorescent marker (DiI or $\mathrm{DiO}$ ) was removed by ultracentrifugation prior to binding and uptake experiments. For studies with fluorescently labeled peptide, the peptide was labeled with a fluorescein isothiocyanate (FITC) at the N-terminus of the peptide (Biosynthesis, Inc).

\subsection{Fluorescence Microscopy:}

Fluorescence microscopy experiments were carried out in 2-well chamber slides using a Zeiss 200M Axiovert optical microscope. Digital images were captured with Image Pro Software. Cells were fixed in 4\% paraformaldehyde in PBS after the PBS rinses. For nLDL uptake experiments which were carried out at $37^{\circ} \mathrm{C}$, cells were fixed for $15 \mathrm{~min}$ at room temperature. For nLDL surface binding experiments which were carried out at $4^{\circ} \mathrm{C}$, cells were fixed for 20 $\min$ at $4{ }^{\circ} \mathrm{C}$. Fluorescent images were obtained at $40 \mathrm{X}$ magnification.

\subsection{Confocal Microscopy:}

Confocal microscopy on dual labeled nLDL (FITC and DiI) was carried out for live and fixed cells on glass coverslips using a Zeiss $510 \mathrm{UV} /$ Vis Meta microscope. Lysotracker Blue $(5 \mu \mathrm{M})$ was added to cells at the start of the experiment. At the conclusion of the experiment, the coverslip was washed four times with PBS. For live cells, the coverslip was mounted onto a 
glass slide and sealed. For fixed cells, fixation was carried out as above and then the coverslip was mounted on a glass slide and sealed. Cells were viewed at 100X magnification.

\subsection{Fluorescence activated cell sorting (FACS) analysis:}

FACS experiments were carried out in 12-well dishes. Cells were incubated with DiO-labeled sLDL at various concentrations and for various periods of time as indicated in the figure legends. At the conclusion of each experiment, cells loaded with DiO-labeled nLDL were washed with PBS and trypsinized. Cells were centrifuged to remove the trypsin and then resuspended in PBS. A Becton Dickinson FACSCaliber instrument was used to assess DiO fluorescence. 10,000 cells per well were excited at $488 \mathrm{~nm}$ and fluorescence was detected at $530 \mathrm{~nm}$. Control cells without DiO-nLDL were used to correct for nonspecific cellular fluorescence.

\subsection{Statistics:}

One way analysis of variance (ANOVA) was used to determine differences in cellular uptake of DiO-labeled nLDL. P-values less than 0.05 were considered significant. Pair-wise differences were assessed using the Tukey follow-up test. 


\section{Results}

\subsection{Characterization of nLDL:}

The 29 amino acid bifunctional peptide was observed to be highly water soluble and readily bound to lipid microemulsions. Unbound peptide was removed by dialysis; the amount of original peptide remaining bound to $\mathrm{nLDL}$ was $82 \pm 9 \%(\mathrm{n}=11)$. FPLC analysis of the $\mathrm{nLDL}$ (Figure 1) indicated particles were primarily intermediate between LDL and HDL in size. In addition, lipid-poor particles smaller than HDL (fractions 17-19) were also observed.

In order to remove lipid-poor peptide complexes from the lipid-rich particles, nLDL were ultracentrifuged at $\mathrm{d}=1.21 \mathrm{~g} / \mathrm{mL}$ and the fraction with density $\leq 1.21 \mathrm{~g} / \mathrm{mL}$ isolated and used in all cell experiments. This resulted in $28 \pm 7 \%(\mathrm{n}=3)$ recovery of the peptide in the $\mathrm{d} \leq 1.21 \mathrm{~g} / \mathrm{mL}$ fraction. Composition of the centrifugally isolated lipid-rich $\mathrm{nLDL}(\mathrm{d} \leq 1.21 \mathrm{~g} / \mathrm{mL}$ fraction) was: peptide, $24 \pm 3 \%$; PC, $23 \pm 3 \%$; TO, $50 \pm 3 \%$, and $\mathrm{CO}, 3 \pm 1 \%(\mathrm{n}=3)$. The composition of the buoyant nLDL particles is consistent with particles in the LDL-HDL size range. Electron microscopy of the isolated nLDL (Figure 1 inset) revealed that the particles had a mean diameter of $10.5 \pm 2.8 \mathrm{~nm}$.

\section{2. $4^{\circ} \mathrm{C}$ Binding of $\mathrm{nLDL}$ to the LDL Receptor:}

Cell binding experiments were carried out at $4^{\circ} \mathrm{C}$ to determine whether nLDL bound to LDLR on the surface of GBM cells. A representative micrograph shown in Figure 2B revealed DiI-labeled nLDL bound to the surface of SF-767 cells. A similar distribution of binding is observed for the binding of DiI-labeled plasma-derived LDL in SF-767 GBM cells (Figure 2D). Cell binding was 
repeated with the U-251 and SF-763 GBM cell lines and yielded a similar binding distribution (data not shown). In the presence of $10 \mathrm{mM}$ suramin, an inhibitor of LDL interaction with LDLR, the binding of DiI-nLDL is blocked (Figure 3A-B), as was previously observed with plasma-derived LDL (Schneider et al., 1982). This suggests that nLDL is binding to the LDLR. Addition of excess unlabeled nLDL to the SF-767 cells competes with plasma-derived LDL for receptor binding and greatly reduces the binding of DiI-labeled plasma-derived LDL to the cell surface (Figure 3C-D), which further supports the premise that nLDL binds to the LDLR.

\section{3. $37^{\circ} \mathrm{C}$ Uptake of nLDL:}

Uptake of the DiI-labeled nLDL particles by SF-767, U-251, and SF-763 GBM cell lines was assessed by incubating cells at $37^{\circ} \mathrm{C}$ for $1,3,6$, and 9 hours $(1.5 \mu \mathrm{M}$ peptide) prior to carrying out fluorescence microscopy. A representative fluorescence microscopy photo series of the SF767 tumor cell line is shown in Figure 4A. DiI-labeled nLDL uptake increases between 1 and 3 hours and appears to saturate at the latter time point. The U-251 and SF-763 cells showed a similar pattern of uptake and saturation (data not shown). Time dependence of nLDL uptake was verified by quantifying uptake of DiO-labeled nLDL (1.5 $\mu \mathrm{M}$ peptide) using FACS analysis. Figure 4B indicates that nLDL uptake by SF-767 cells saturates between 3 and 6 hours, consistent with the microscopy data.

The concentration dependence of nLDL uptake by SF-767 cells was assessed with DiO-labeled sLDL over a range of $0.1 \mu \mathrm{M}$ to $10 \mu \mathrm{M}$ peptide. Fluorescence was quantified using FACS analysis. Figure 4C indicates a saturability of nLDL uptake at higher concentrations of peptide. 


\subsection{Co-localization of Peptide and Lipid in SF-767 Cells:}

Confocal microscopy was utilized to determine whether the lipid and peptide moieties of nLDL co-localize in SF-767 cells (Figure 5). Dual labeled nLDL particles using FITC to label the peptide and DiI to label the lipid were incubated with cells for $3 \mathrm{~h}$ at $37^{\circ} \mathrm{C}$. Figures $5 \mathrm{~A}-\mathrm{B}$ represent fixed cells and demonstrate that the peptide and lipid have both entered cells and appear to co-localize. Similar results are obtained for living cells after $1 \mathrm{~h}$ incubation at $37^{\circ} \mathrm{C}$ (Figure 5C-E). Comparison of images in Figures 5C, D, and E suggest that both peptide and lipid co-localize in unfixed cells. Lysotracker Blue was used to identify lysosomes and the comparison of Figure 5F with Figures 5C-D suggests that endocytosed peptide and lipid are found in the lysosomes. This is further evidence of receptor-mediated uptake of the nLDL particles.

\subsection{Comparison of nLDL Uptake by SF-767, SF-763, and U-251 Cells:}

It was previously observed that different GBM cell lines have variable numbers of LDL receptors per cell (Maletinska et al., 2000). To determine whether cell receptor number influenced nLDL uptake, three GBM cell lines SF-763, SF-767, and U-251 cells having 950,000, 288,000 , and 128,000 receptors per cell, respectively, were examined. Differences in nLDL uptake were quantified using FACS analysis on DiO-labeled nLDL incubated with cells for $3 \mathrm{~h}$ at $1.5 \mu \mathrm{M}$ peptide. Figure 6 shows that U-251 cells take up significantly less fluorescently labeled nLDL than SF-767 and SF-763 cells. On the other hand, there was a small but significant difference in nLDL uptake between SF-767 and SF-763 cells where the latter show slightly higher uptake. 


\section{Discussion}

High-grade gliomas are difficult to treat since they grow aggressively and islets of cells often remain after surgical excision of the tumor. These residual cells lead to recurrence of the tumor. In recent years the emphasis for treatment of gliomas, as well as other types of tumors, has been the identification of specific molecular targets for the delivery of drugs. Such molecular targets would minimize toxic effects on surrounding normal tissue. The epidermal growth factor receptor (Barth et al., 2002), platelet derived growth factor receptor (Hermanson et al., 1992), fibroblast growth factor receptor (Morrison et al., 1994), human epidermal receptor type 2 (Mineo et al., 2004), and interleukin-13 receptor (Mintz et al., 2002) have been shown to be upregulated in glioma cells. We have previously shown that human GBM cell lines express high levels of LDL receptors (Maletinska et al., 2000) and demonstrated that boronated protoporphryn is delivered to the SF-767 GBM cell line by LDL (Callahan et al., 1999). LDL receptors are sparse in normal brain tissue (Pitas et al., 1987) suggesting that the LDL receptor represents a unique target that can be used for delivery of chemotherapeutics targeted to tumor cells. ApoB100 on the surface of the LDL is the ligand for the receptor. However, because plasma-derived LDL cannot be obtained in large quantities and the apoB-100 protein is difficult to work with, the use of synthetic particles made with small proteins or peptides is desirable.

To generate a synthetic nano-LDL, our approach utilized a bifunctional peptide that possesses the LDL binding domain linked to an 18 amino acid amphipathic alpha helix previously described by Anantharamaiah et al (1985). This amphipathic helix avidly binds to lipid thus stably anchoring the LDLR ligand on the surface of the lipid microemulsion. Because of the 
amphipathtic nature of the peptide, it is highly soluble in aqueous medium but readily binds to lipid microemulsion. This approach is different from that of Baille et al (2002) who used only the LDLR binding domain capped with retinoic acid and cholesterol; the peptide was not soluble in aqueous medium.

We have shown that the nLDL formed with the bifunctional peptide has the ability to recognize the LDLR which is a prerequisite for targeted delivery of drugs to cells overexpressing the LDLR. Synthetic nLDL bound to the surface of GBM cells and binding could be blocked by suramin (Schneider et al., 1982), a molecule that inhibits LDL-LDLR interactions. The nLDL also was effective in competing for the LDLR in experiments with plasma-derived LDL and drastically reduced LDL binding to the receptor. Both of these characteristics are consistent with the specific binding of nLDL to LDLR. Synthetic nLDL uptake using dual labeled particles, i.e., fluorescently labeled lipid and fluorescently-labeled peptide, indicated that both moieties colocalize in the cell. This also provides evidence that the particles enter cells intact. The use of Lysotracker established that the nLDL particles trafficked to the lysosome as expected for LDLR-mediated uptake of particles (Goldstein et al., 1985). In this regard, our results are similar to the findings of Callahan et al. (1999) who showed that boronated protophorphyrin introduced into SF-767 cell cultures localized in the lysosome and that uptake of the pro-drug required both the presence of serum LDL and cell surface LDLR.

The present studies with nLDL suggest that uptake of targeted LDL-like particles is dependent on the number of receptors on the cell surface. As previously reported, the number of LDLR in GBM cell lines tested in our study ranged from 125,000 per cell for U-251 cells to 950,000 for 
SF-763; the SF-767 cell had intermediate numbers of receptors $(288,000)$ (Maletinska et al., 2000). Accumulation of fluorescently labeled nLDL in both SF-763 and SF-767 was twice that of U-251 cells. However, although SF-763 cells have approximately 3-times the number of LDLR per cell than SF-767 cells, their accumulation was only 6\% greater than that of SF-767. This can be explained, in part, by the observation of Maletinska et al (2000) that the LDLR binding affinity of SF-767 cells is much greater than that for SF-763 cells. Additionally, there could be differences in LDLR internalization and recycling rate that could account for the relatively lower accumulation of nLDL in SF-763 cells.

Plasma LDL and HDL particles are not found in cerebral spinal fluid (Roheim et al., 1979, Pitas et al., 1987) because they do not cross the blood-brain barrier. Since systemic delivery would limit the effective distribution of nLDL, the particles can be delivered by convection enhanced delivery techniques (Hall et al., 2003) directly to the region of the tumor. Since nLDL particles formed with our bifunctional peptide are small nano-particles $(\sim 10.5 \mathrm{~nm})$ it is likely that their diffusion will be more optimal than plasma LDL since there is an inverse relationship between particle size and its diffusion in tissue. Because of their hydrophobic core, the nLDLs are expected to provide a mechanism for the transport of hydrophobic drugs. In addition, hydrophilic drugs can be converted to hydrophobic pro-drugs by chemical modifications as suggested by several laboratories (Lundberg et al., 2003, Firestone et al., 1984, Dubowchik and Firestone, 1995) thus increasing the arsenal of drugs that can be potentially targeted to GBM via nLDL. The bifunctional peptide-engineered synthetic nLDL is a promising approach for targeting anticancer drugs to GBM. 


\section{Acknowledgements}

The authors thank Terren Trott, Chris Rosen, and Peter Wang for their technical assistance with the project and Dr. Robert Ryan for helpful discussions. This work was supported in part by CHORI Institutional Funds and the United States Department of Energy under contracts DEACO3-76SF00098 and DE-ACO2-05CH11231.

\section{References}

Anantharamaiah, G. M., Jones, J. L., Brouillette, C. G., Schmidt, C. F., Chung, B. H., Hughes, T. A., Brown, A. S., Segrest, J. P. 1985. Studies of synthetic peptide analogs of the amphipathic helix: structure of complexes with dimyristoyl phosphatidylcyholine. J Biol Chem, 260, 10248-10255.

Baillie, G., Owens, M. D., Halbert, G. W. 2002. A synthetic low density lipoprotein particle capable of supporting U937 proliferation in vitro. J Lipid Res, 43, 69-73.

Barth, R., Yang, W., Adams, D., Rotaru, J., Shukla, S., Sekido, M., Tjarks, W., Fenstermaker, R., Ciesielski, M., Nawrocky, M., Coderre, J. 2002. Molecular targeting of the epidermal growth factor receptor for neutron capture therapy of gliomas. Cancer Res, 62, 31593156.

Callahan, D. E., Forte, T. M., Afzal, S. J., Deen, D. F., Kahl, S. B., Bjornstad, K. A., Bauer, W. F., Blakely, E. A. 1999. Boronated protoporphyrin (BOPP): localization in lysosomes of the human glioma cell line SF-767 with uptake modulated by lipoprotein levels. Int J Radiat Oncol Biol Phys, 45, 761-771. 
Chen, Y., Hughes-Fulford, M. 2001. Human prostate cancer cells lack feedback regulation of low-density lipoprotein receptor and its regulator, SREBP2. Int J Cancer, 91, 41-45.

Chu, A. C. Y., Tsang, S. Y., Lo, E. H. K., Fung, K. P. 2001. Low density lipoprotein as a targeted carrier for doxorubicin in nude mice bearing human hepatoma HepG2 cells. Life Sci, 70, 591-601.

Dubowchik, G. M., Firestone, R. A. 1995. Improved cytotoxicity of antitumor compounds deliverable by the LDL pathway. Bioconj Chem, 6, 427-439.

Firestone, R. A. 1994. Low-density lipoprotein as a vehicle for targeting antitumor compounds to cancer cells. Bioconj Chem, 5, 105-113.

Firestone, R. A., Pisano, J. M., Falck, J. R., McPhaul, M. M., Krieger, M. 1984. Selective delivery of cytotoxic compounds to cells by the LDL pathway. J Med Chem, 27, 10371043.

Forte, T. M., Nordhausen, R. W. 1986. Electron microscopy of negatively stained lipoproteins. Methods Enzymol, 128, 442-457.

Gal, D., McDonald, P. C., Porter, J. C., Simpson, E. R. 1981. Cholesterol metabolism in cancer cells in monolayer culture. III. Low-density lipoprotein metabolism. Int J Cancer, 28, 315-319.

Goldstein, J. L., Brown, M. S., Anderson, R. G. W., Russell, D. W., Schneider, W. J. 1985. Receptor-mediated endocytosis: concepts emerging from the LDL receptor system. Ann Rev Cell Biol, 1, 1-39.

Grundy, S. M. 1990. Cholesterol and atherosclerosis: diagnosis and treatment, Philadelphia, J.B. Lippincott Company. 
Hall, W., Rustamzadeh, E., Asher, A. 2003. Convection-enhanced delivery in clinical trials. Neurosurg Focus, 14, e2.

Hayavi, S., Halbert, G. W. 2005. Synthetic low-density lipoprotein, a novel biomimetic lipid supplement for serum-free tissue culture. Biotechnol Prog, 21, 1262-1268.

Hermanson, M., Funa, K., Hartman, M., Claesson-Welsh, L., Heldin, C., Westermark, B., Nister, M. 1992. Platelet-derived growth factor and its receptors in human glioma tissue: expression of messenger RNA and protein suggests the presence of autocrine and paracrine loops. Cancer Res, 52, 3213-3219.

Ho, Y. K., Smith, R. G., Brown, M. S., Goldstein, J. L. 1978. Low-density lipoprotein (LDL) receptor activity in human acute myelogenous leukemia cells. Blood, 6, 1099-1114.

Innerarity, T. L., Pitas, R. E., Mahley, R. W. 1986. Lipoprotein-receptor interactions. Methods Enzymol, 129, 542-565.

Ji, B., Peacock, G., Lu, D. R. 2002. Synthesis of cholesterol-carbonane conjugate for targeted drug delivery. Bioorg Med Chem Lett, 12, 2455-2458.

Lowry, O. H., Rosebrough, N. J., Farr, A. L., Randall, R. J. 1951. Protein measurement with the folin phenol reagent. J Biol Chem, 193, 265-275.

Lundberg, B. 1987. Preparation of drug-low density lipoprotein complexes for delivery of antitumoral drugs via the low density lipoprotein pathway. Cancer Res, 47, 4105-4108.

Lundberg, B. 1994. Cytotoxic activity of two new lipophilic steroid nitrogen carbamates incorporated into low-density lipoprotein. Anticancer Drug Design, 9, 471-476.

Lundberg, B., Risovic, V., Ramaswamy, M., Wasan, K. 2003. A lipophilic paclitaxel derivative incorporated in a lipid emulsion for parenteral administration. J Control Release, 86, 93100. 
Lundberg, B., Suominen, L. 1984. Preparation of biologically active analogs of serum low density lipoprotein. J Lipid Res, 25, 550-558.

Maletinska, L., Blakely, E. A., Bjornstad, K. A., Deen, D. F., Knoff, L. J., Forte, T. M. 2000. Human glioblastoma cell lines: levels of low-density lipoprotein receptor and low-density lipoprotein receptor-related protein. Cancer Res, 60, 2300-2303.

Masquelier, M., Lundberg, B., Peterson, C., Vitols, S. 2006. Cytotoxic effect of a lipophilic alkylating agent after incorporation into low density lipoprotein or emulsions: studies in human leukemic cells. Leuk Res, 30, 136-144.

Mineo, J., Bordron, A., Quintin-Roue, I., Loisel, S., Ster, K., Buhe, V., Lagarde, N., Berthou, C. 2004. Recominant humanised anti-HER2/neu antibody (Herceptin) induces cellular death of glioblastomas. Br J Cancer, 91, 1195-1199.

Mintz, A., Gibo, D., Slagle-Webb, B., Nd, C., Debinski, W. 2002. IL-13Ralpha2 is a gliomarestricted receptor for interleukin-13. Neoplasia, 4, 388-399.

Morrison, R., Yamaguchi, F., Bruner, J., Tang, M., Mckeehan, W., Berger, M. 1994. Fibroblast growth factor receptor gene expression and immunoreactivity are elevated in human glioblastoma multiforme. Cancer Res, 54, 2794-2799.

Nakagawa, T., Ueyama, Y., Nozaki, S., Yamashita, S., Menju, M., Funahashi, T., KamedaTakemura, K., Kubo, M., Tokunaga, K., Tanaka, T., Yagi, M., Matsuzawa, Y. 1995. Marked hypocholesterolemia in a case with adrenal adenoma-enhanced catabolism of low density lipoprotein (LDL) via the LDL receptors of tumor cells`. J Clin Endocrinol Metab, 80, 92-96. 
Niendorf, A., Nagele, H., Gerding, D., Meyer-Pannwitt, U., Gebhardt, A. 1995. Increased LDL receptor mRNA expression in colon cancer is correlated with a rise in plasma cholesterol levels after curative surgery. Int J Cancer, 61, 461-464.

Pitas, R. E., Boyles, J. K., Lee, S. H., Hui, D., Weisgraber, K. H. 1987. Lipoproteins and their receptors in the central nervous system. J Biol Chem, 262, 14352-14360.

Pitas, R. E., Innerarity, T. L., Weinstein, J. N., Mahley, R. W. 1981. Acetoacetylated lipoproteins used to distinguish fibroblasts from macrophages in vitro by fluorescence microscopy. Arteriosclerosis, 1, 177-185.

Rensen, P. C. N., de Vrueh, R. L. A. D., Kuiper, J., Bijsterbosch, M. K., Biessen, E. A. L., Berkel, T. J. C. V. 2001. Recombinant lipoproteins: lipoprotein-like lipid particles for drug targeting. Adv Drug Deliv Rev, 47, 251-276.

Roheim, P. S., Carey, M., Forte, T., Vega, G. L. 1979. Apolipoproteins in human cerebrospinal fluid. Proc Natl Acad Sci U S A, 76, 4646-4649.

Rudling, M. J., Angelin, B., Peterson, C. O., Collins, V. P. 1990. Low density lipoprotein receptor activity in human intracranial tumors and its relation to the cholesterol requirement. Cancer Res, 50, 483-487.

Schneider, W. J., Beisiegel, U., Goldstein, J. L., Brown, M. S. 1982. Purification of the low density lipoprotein receptor, an acidic glycoprotein of 164,000 molecular weight. J Biol Chem, 257, 2664-2673.

Segrest, J. P., Jones, M. K., Loof, H. D., Dashti, N. 2001. Structure of apoliprotein B-100 in low density lipoproteins. J Lipid Res, 42, 1346-1367. 
Stranzl, A., Schmidt, H., Winkler, R., Kostner, G. M. 1997. Low-density lipoprotein receptor mRNA in human breast cancer cells: influence by PKC modulators. Breast Cancer Res Treat, 42, 195-205.

Tatidis, L., Masquelier, M., Vitols, S. 2002. Elevated uptake of low density lipoprotein by drug resistant human leukemic cell lines. Biochem Pharmacol, 63, 2169-2180.

Vitols, S., Gharton, G., Ost, A., Peterson, C. 1984. Elevated low density lipoprotein receptor activity in leukemic cells with monocytic differentiation. Blood, 83, 1186-1193.

Vitols, S., Norgren, S., Juliusson, G., Tatidis, L., Luthman, H. 1994. Multilevel regulation of low-density lipoprotein receptor and 3-hydroxy-3-methylglutaryl coenzyme A reductase gene expression in normal and leukemic cells. Blood, 84, 2689-2698.

Vitols, S., Peterson, C., Larsson, O., Holm, P., Aberg, B. 1992. Elevated uptake of low density lipoproteins by human lung cancer tissue in vivo. Cancer Res, 52 .

Vitols, S., Soderberg-Reid, K., Masquelier, M., Sjostrom, B., Peterson, C. 1990. Low density lipoprotein for delivery of a water-soluble alkylating agent to malignant cells: in vitro and in vivo studies of a drug-lipoprotein complex. Br J Cancer, 62, 724-729.

Vitols, S. G., Masquelier, M., Peterson, C. O. 1985. Selective uptake of a toxic lipophilic anthracycline derivative by the low-density lipoprotein receptor pathway in cultured fibroblasts. J Med Chem, 28, 451-454. 
Figures Legends:

Figure 1: Fast protein liquid Chromatography of nLDL. There is a large component of nLDL particles intermediate in size between plasma LDL and HDL particles; lipid-poor component is visible in fractions 17-19. Electron microscopy (inset) revealed particles $10.5 \pm 2.8 \mathrm{~nm}$ diameter.

Figure 2: Representative images of cell surface binding of DiI-labeled nLDL and plasma-derived LDL. (A) bright field image of cells and (B) corresponding fluorescence image of DiI-labeled $\mathrm{nLDL}(1.5 \mu \mathrm{M}$ peptide), (C) bright field image and (D) corresponding fluorescence image of DiI-labeled plasma-derived LDL ( $10 \mu \mathrm{g} / \mathrm{mL}$ protein). Experiments were carried out at $4^{\circ} \mathrm{C}$ for 3 h. The punctate distribution of DiI-labeled nLDL on the cell surface is similar to that of plasmaderived LDL. This experiment was repeated three additional times with separate nLDL batches and yielded similar results.

Figure 3: Binding of nLDL to LDLR of SF-767 cells. Cells were incubated with DiI-labeled nLDL (1.5 $\mu \mathrm{M}$ peptide) in the absence (A) and presence (B) of $10 \mathrm{mM}$ suramin. Presence of suramin inhibits binding of DiI-labeled nLDL to cells. Cells were incubated with DiI-labeled plasma-derived LDL (0.5 $\mu \mathrm{g} / \mathrm{mL}$ protein), (C), and competed with 100-fold excess of nLDL, (D). Excess nLDL blocks the binding of plasma-derived LDL. All experiments were carried out at $4^{\circ} \mathrm{C}$ for $1 \mathrm{~h}$.

Figure 4: Representative experiments illustrating that nLDL uptake by SF-767 cells is time and concentration dependent. (A) Fluorescence microscopy shows uptake of DiI-labeled nLDL (1.5 
$\mu \mathrm{M}$ peptide) is time dependent. Uptake of DiI-labeled lipids was tested at 1, 3, 6, and $9 \mathrm{~h}$. SF767 cells were fixed with 4\% paraformaldehyde at each time point prior to microscopy. The experiment was repeated with a separately produced batch of nLDL and yielded identical results. (B) FACS analysis data indicate that uptake of DiO-labeled nLDL (1.5 $\mu \mathrm{M}$ peptide) is time dependent. SF-767 cells were incubated for $1,3,6$, and $9 \mathrm{~h}$ at $37^{\circ} \mathrm{C}$ with $\mathrm{nLDL}$ particles previously labeled with DiO. Data represents mean $\pm \mathrm{SD}$ of three separate wells. (C) FACS analysis data show uptake of DiO-labeled nLDL particles is concentration dependent. Cells were incubated for $3 \mathrm{~h}$ at $37^{\circ} \mathrm{C}$ with varying concentrations of $\mathrm{nLDL}$ particles $(0.1,1,5,10 \mu \mathrm{M}$ peptide) that had been previously labeled with DiO. Data represents mean $\pm \mathrm{SD}$ of three separate wells. The data suggests saturation at approximately $5 \mu \mathrm{M}$ peptide. This experiment was repeated two additional times with separate $\mathrm{nLDL}$ batches and yielded identical results.

Figure 5: Confocal microscopy of SF-767 cells reveals colocalization of peptide and lipid in lysosomes. The representative images in A and B were obtained from cells fixed after $3 \mathrm{~h}$ incubation of cells with dual-labeled nLDL (1.5 $\mu \mathrm{M}$ peptide) where the peptide carried the FITC label and lipid the DiI label; (A) FITC label of peptide, and (B) DiI-label in lipids. The representative images in C-F were obtained from living SF-767 cells after $1 \mathrm{~h}$ incubation with dual labeled nLDL (1.5 $\mu \mathrm{M}$ peptide); (C) FITC-labeled peptide, (D) DiI-labeled lipids, (E) images in C and D merged to show co-localization of peptide and lipid and (F) Lysotracker Blue image for localization of lysosome reveals co-localization of the peptide and lipid in lysosomes. 
Figure 6: Uptake of DiO-labeled nLDL is dependent on LDL receptor number. Cells were incubated for $3 \mathrm{~h}$ at $37^{\circ} \mathrm{C}$ with nLDL ( $1.5 \mu \mathrm{M}$ peptide) previously labeled with DiO. At the conclusion of the experiment, cells were trypsinized and resuspended in PBS. Data for each time point represent the mean \pm SD of three separate wells. Significant differences in fluorescence were present for all pairwise comparisons $(\mathrm{p}<0.05)$. This experiment was repeated using a separate batch of nLDL and yielded similar results. 
Figures

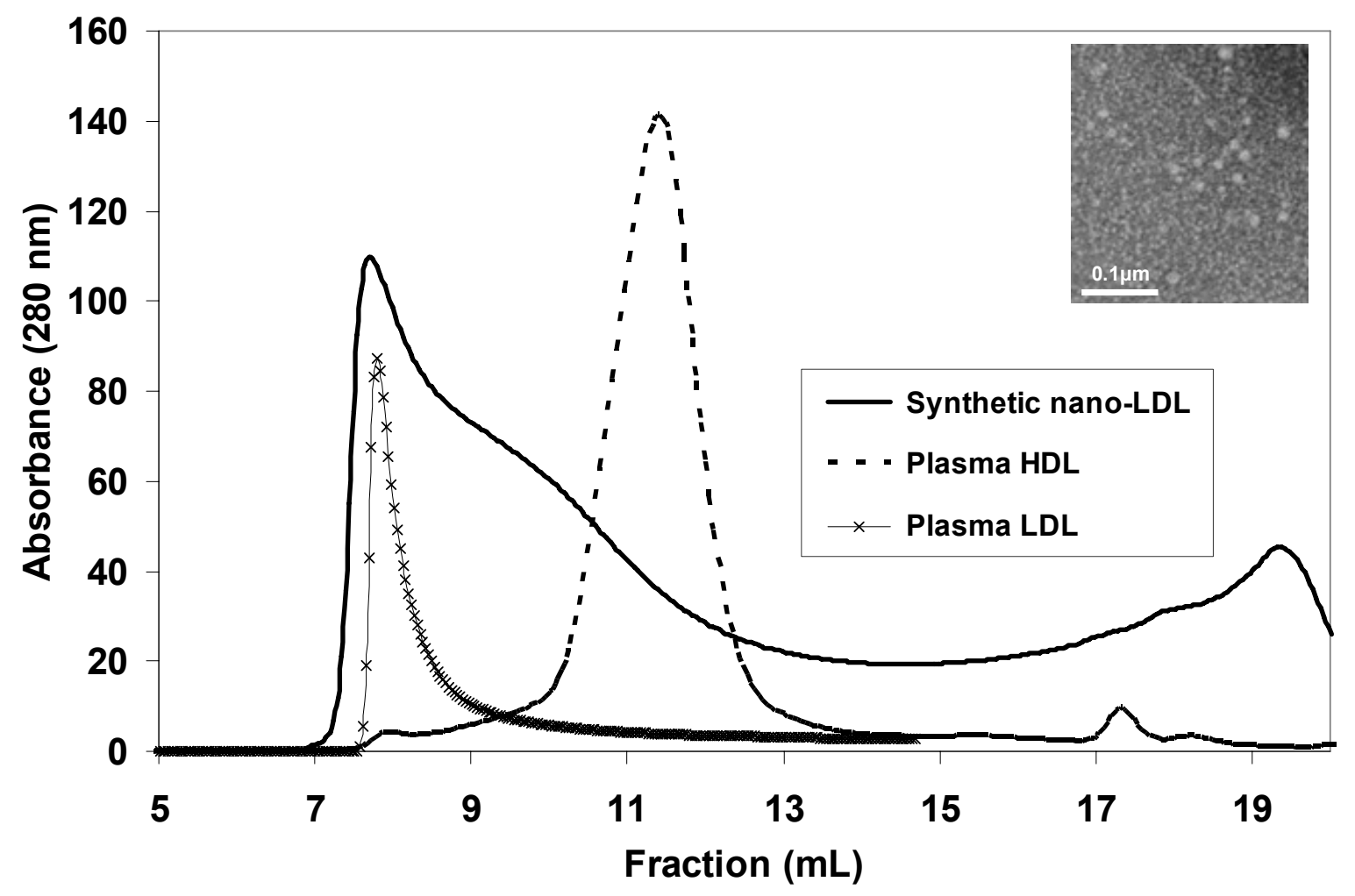

Figure 1 


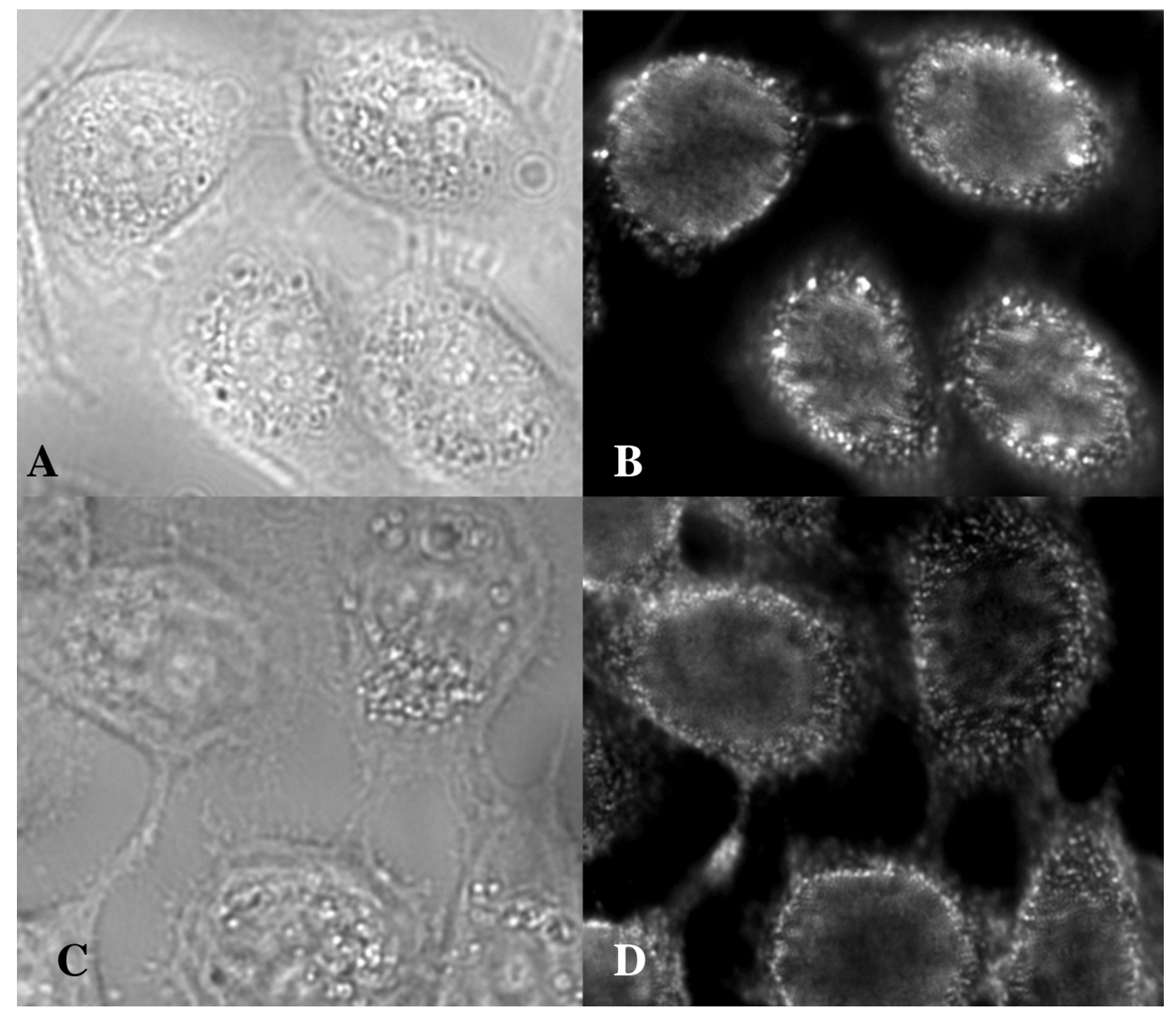

Figure 2 


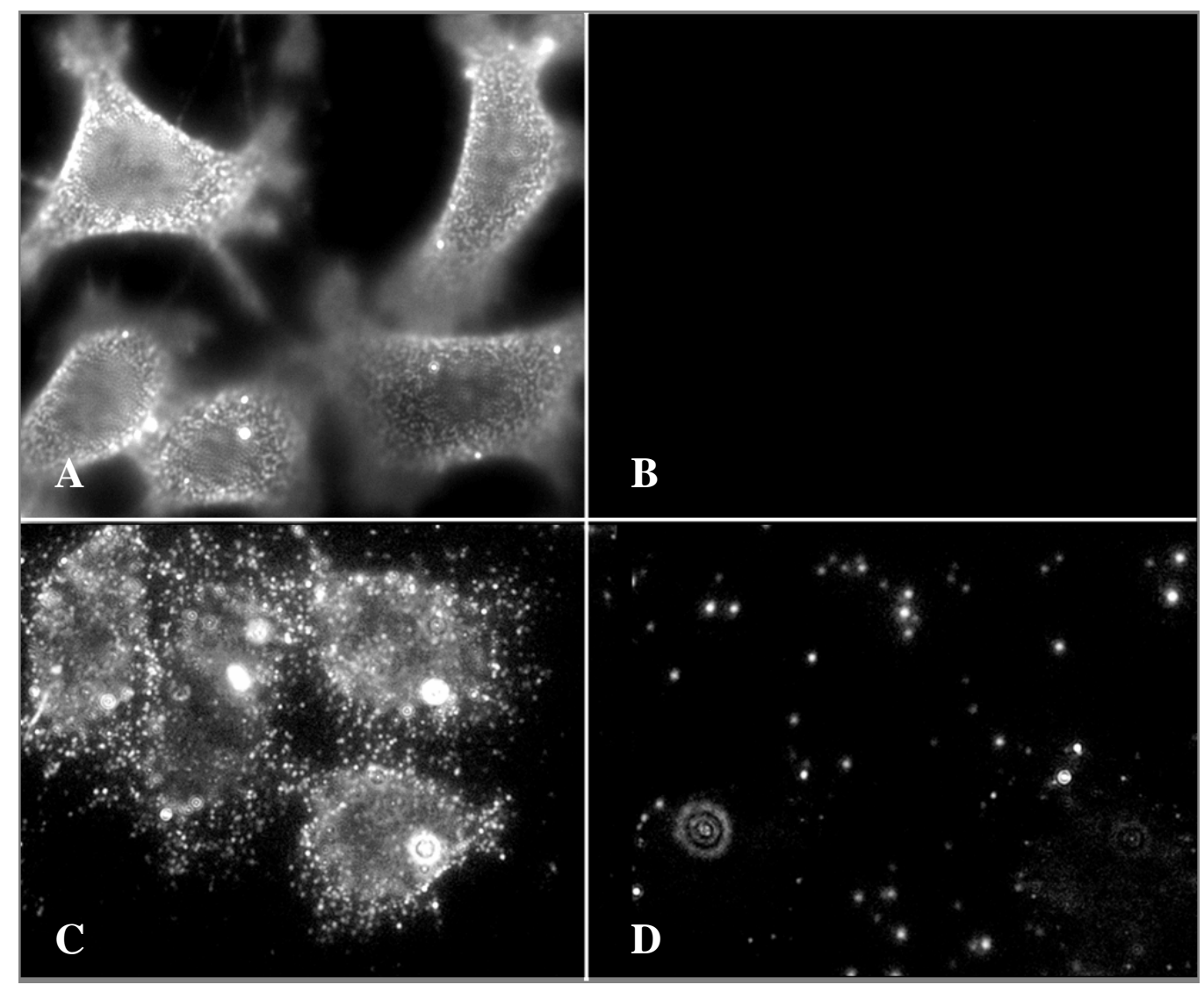

Figure 3 
A

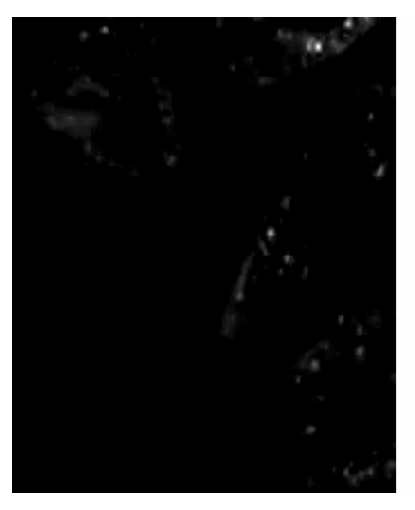

$1 \mathrm{~h}$

B
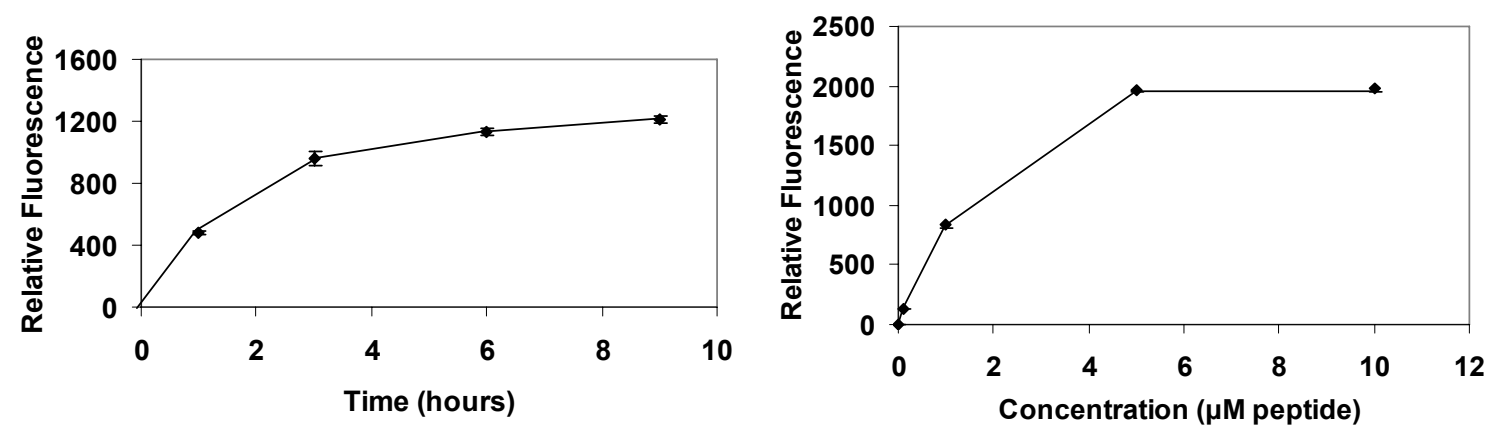

Figure 4 


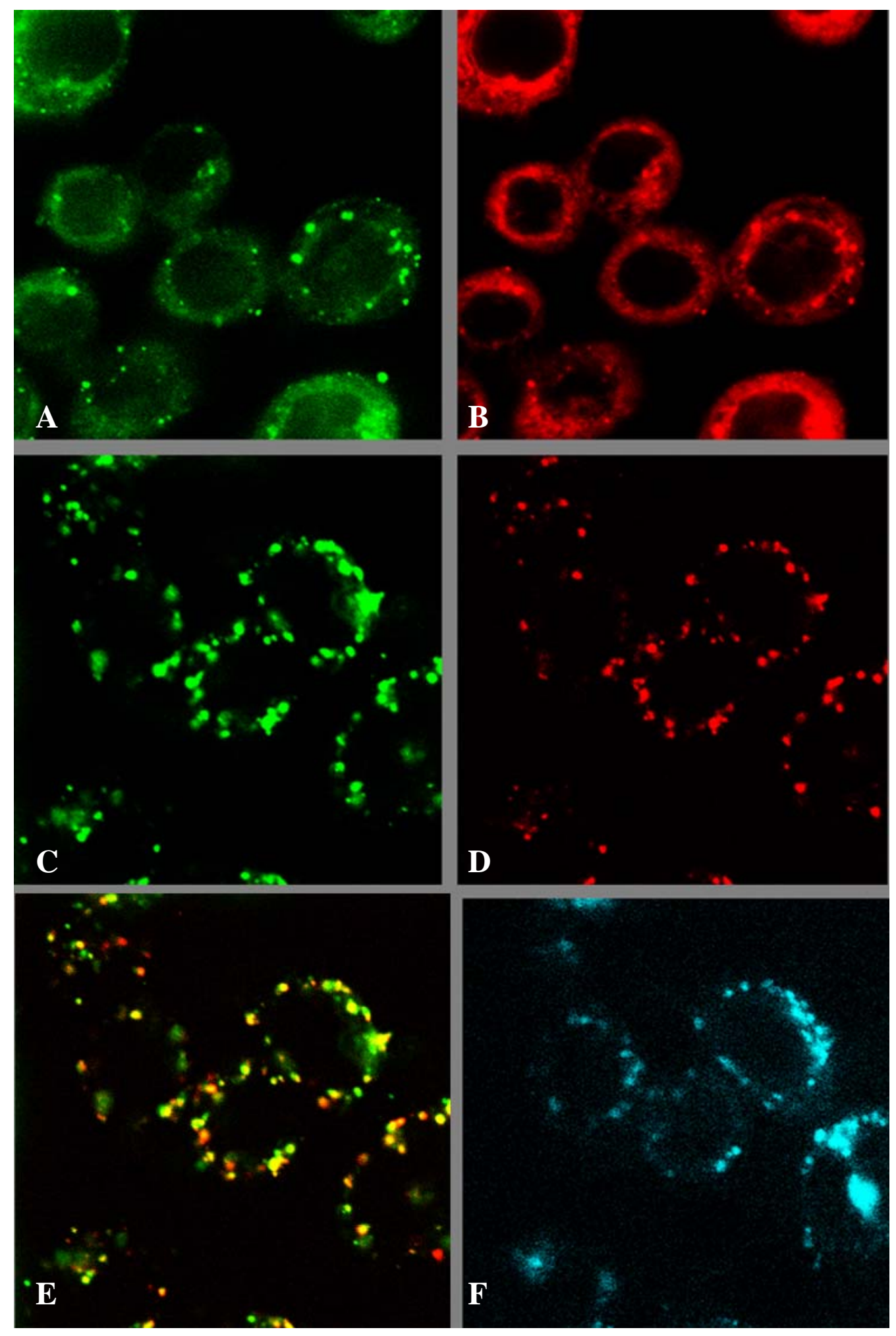

Figure 5

30 


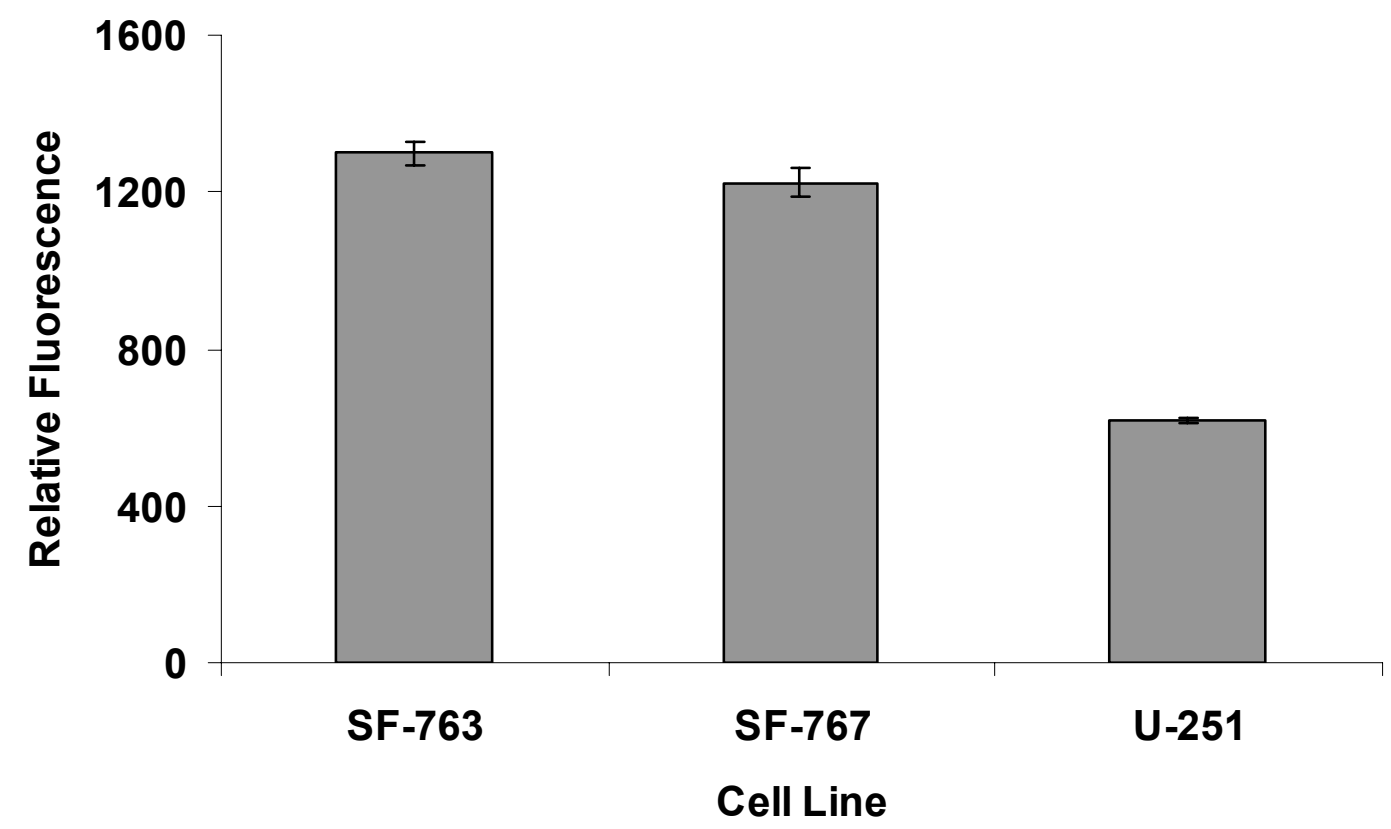

Figure 6 